\title{
SINDICALISMO AGRARISTA Y NACIONALISMO VASCO $(1933-1936)^{1}$
}

\section{Peasant association and basque nationalism (1933-1936)}

\author{
MIKEL AIZPURU \\ Universidad del País Vasco/Euskal Herriko Unibertsitatea \\ mikel.aizpuru@ehu.eus
}

Cómo citar/Citation

Aizpuru, M. (2017)

Sindicalismo agrarista y nacionalismo vasco (1933-1936).

Historia y Política, 38, 259-287.

doi: https://doi.org/10.18042/hp.38.09

(Recepción: 04/02/2016. Evaluación: 21/06/2016. Aceptación: 30/11/2016. Publicación: 10/11/2017)

\section{Resumen}

Las elecciones generales del periodo republicano español confirmaron un hecho novedoso: la consolidación del nacionalismo vasco en el espacio rural. Entre las razones de dicho triunfo se ha apuntado la aparición en 1933 en Guipúzcoa de la asociación de campesinos denominada Euzko Nekazari Bazkuna (ENB, Federación de Campesinos Vascos). Este artículo pretende justamente analizar las relaciones entre ENB, el PNV y Solidaridad de Trabajadores Vascos, extendiendo además el

1 Este trabajo se ha realizado en el seno del grupo de investigación del Sistema Universitario Vasco IT-708-13, dirigido por el catedrático Luis Castells, en el marco de proyecto de investigación «El peso de las percepciones del pasado en la política vasca. Violencia política, memoria e identidad territorial» (MINECO HAR2014-51956-P), cuyo investigador principal es el catedrático Antonio Rivera. Una primera versión de este artículo se presentó al XV Congreso Internacional de Historia Agraria (Lisboa, 27-30 de enero de 2016). Agradezco a los evaluadores de la revista los consejos e indicaciones que han permitido mejorar su contenido. 
campo de estudio a la provincia de Vizcaya, donde en 1935 se formó Euzko Nekazari Alkartasuna (Solidaridad de Campesinos Vascos). También pretende subrayar el hecho de que solo cuando los campesinos asumieron la necesidad de agruparse tuvo éxito esta propuesta asociativa.

\title{
Palabras clave
}

Sindicalismo agrario; nacionalismo vasco; República; Solidaridad de Trabajadores Vascos.

\begin{abstract}
The general elections of Spanish republican period confirm a novelty, the consolidation of Basque nationalism in rural areas. Among the reasons for this success is the appearance of the peasant association called Euzko Nekazari Bazkuna (ENB, Basque Peasants Federation) in 1933 in Guipuzcoa. This article's aim is to analyze the relationship between ENB, the PNV and Solidaridad de Trabajadores Vascos, also extending the field of study to the province of Vizcaya, where in 1935 Euzko Nekazari Alkartasuna (Solidarity of Basque Peasants) was formed. It also seeks to emphasize the fact that this associative proposal only succeed when peasants decided to group by themselves.
\end{abstract}

\section{Keywords}

Peasant association; Basque nationalism; Republica; Solidaridad de Trabajadores Vascos. 


\section{SUMARIO}

I. INTRODUCCIÓN. II. EL DESARROLLO DEL SINDICALISMO AGRARIO AUTÓNOMO EN GUIPÚZCOA. III. LA ACTUACIÓN PRÁCTICA DEL SINDICALISMO NEKAZARI. IV. EUZKO NEKAZARI ALKARTASUNA, LAS LIMITACIONES DE UN PROCESO DESDE ARRIBA EN VIZCAYA. V. EL DISCURSO NEKAZARI Y LOS LÍMITES DE SU CAPACIDAD DE ATRACCIÓN. VI. CONCLUSIÓN. BIBLIOGRAFÍA.

\section{INTRODUCCIÓN}

El nacionalismo vasco ha mostrado desde su aparición pública en la década final del siglo XIX una atención intermitente por la cuestión agraria. Esa atención, además, respondía más a motivos ideológicos que a preocupaciones de índole social y económica. De hecho, el mundo agrícola se presentaba a ojos de los primeros nacionalistas como un ámbito idílico donde apenas existían conflictos ${ }^{2}$. Tal vez por ello, y en contraposición al ámbito industrial, donde en 1911 se creó el sindicato Solidaridad de Obreros Vascos, no hubo una política específica sobre el agro vasco al menos hasta los años de la Segunda República.

El espacio agrario de la cornisa cantábrica vasca estaba compuesto de forma mayoritaria por campesinos parcelarios que cultivaban sus pequeñas explotaciones en régimen de arrendamiento. Salvo un reducido sector de jornaleros que compartían espacio, vida, trabajo y parentesco con las familias campesinas, el resto del sector estaba formado por pequeños propietarios. Un relieve accidentado, una edafología poco profunda, una climatología lluviosa y el pequeño tamaño de las parcelas provocaron que solo una utilización intensiva de la mano de obra familiar permitiese la supervivencia de los caseríos vascos y esta circunstancia únicamente fue posible porque el policultivo y la pluriactividad rural fue acompañada de una corriente permanente de expulsión de los excedentes humanos que generaba este modelo de vida. Este universo experimentó profundos cambios como consecuencia de los efectos de la transformación económica, social, cultural y política que se produjo desde el último tercio del siglo xix, tanto en el País Vasco, como en España y en el mundo ${ }^{3}$. El incremento de la competitividad global y la progresiva

Elorza (1977).

3 Legorburu, (1993); Delgado (2009), y Berriochoa (2014). 
integración de los mercados provocaron una cada vez mayor especialización de la producción, y el territorio vasco vio como se incrementaba el peso de su tejido industrial. Ahora bien, esta realidad no implicaba que el sector primario permaneciese pasivo. De hecho, frente a la visión tradicional que subrayaba la rutina y el inmovilismo de la actividad agrícola en el ámbito vasco, los últimos estudios subrayan la capacidad de adaptación del campesino parcelario cantábrico a una nueva situación, caracterizada por el predominio de las actividades industriales y del sector servicios. Conviene no olvidar, por otra parte, que todavía en 1930, un 30,2 \% de la población activa guipuzcoana y el $22,1 \%$ de la vizcaína se dedicaban al sector primario ${ }^{4}$, sector que, aunque incluía la minería y la pesca, estaba orientado fundamentalmente a la agricultura y ganadería. Hay que subrayar, de igual manera, que dichas estadísticas de forma habitual no incluían ni a mujeres ni a menores como elementos productivos de la sociedad.

Uno de las novedades que experimentó dicho sector a comienzos del siglo $\mathrm{xx}$ fue la aparición de un nuevo tejido asociativo agrario que completó y/o sustituyó al tradicional entramado de suaro(s) —asociaciones de seguros contra incendios y ermandadeak, (contra la muerte del ganado)—. En 1907 se creó en Guipúzcoa una red semipública de seguros contra la mortalidad del ganado vacuno, Anaitasuna, y poco antes, en 1904, se inició el proceso constituyente del sindicalismo agrario católico vasco, los Alkartasuna ${ }^{5}$. Aunque estas estructuras recibieron el nombre de sindicatos, se trataba, en la inmensa mayoría de los casos, de entidades cooperativas orientadas al ahorro y a la compra de bienes de equipo, abonos y piensos para los socios de las mismas ${ }^{6}$. Estas asociaciones experimentaron un importante crecimiento a raíz de la Ley de Sindicatos Agrícolas de enero de 1906 y la creación de la Federación Agrícola Vasco-Navarra ${ }^{7}$. No existe una contabilidad rigurosa del número de asociaciones, porque las estadísticas ofrecen unos números dispares ${ }^{8} \mathrm{y}$, sobre

\footnotetext{
Mikelarena (1993): 419.

Gobierno Vasco (2009): 63-64.

Arrieta (1998): 220-248.
}

7 Berriochoa (2014): 406-435. No tenemos más noticias sobre la existencia o funcionamiento de dicha federación, por lo que presumimos que tuvo una vida extremadamente efímera. Hay que esperar hasta 1928 para que se crease la Federación Agraria Vasco-Navarra, con sede social en Vitoria (Arrieta, 1998: 230).

8 Xabier Etxeberria (2015) ha tratado de esbozar una primera síntesis de la difusión del sindicalismo católico en las Provincias Vascongadas, señalando las dificultades sobre la fiabilidad de las fuentes. En 1915 existían en Guipúzcoa, según el censo del Instituto de Reformas Sociales (1915), 44 sindicatos agrícolas y cajas rurales, otras seis 
todo, porque cada provincia eligió un modelo diferente: en Álava se optó por una única organización, el profesional Sindicato Agrícola Alavés9 (1905). En Vizcaya, tras unos inicios difusos ${ }^{10}$, centrados en las asociaciones locales, en 1906 se fundó el Sindicato Agrícola Vizcaíno, reconvertido en 1916 en Federación Católica Agraria de Vizcaya ${ }^{11}$, mientras que en Guipúzcoa se generó un modelo más descentralizado, aunque existiese formalmente la federación desde 1906. La Federación Católico Social Agraria Navarra (1910) se orientó hacia las cajas rurales y al cooperativismo ${ }^{12}$.

Se trataba en la mayoría de los casos de modelos creados de arriba abajo, tutelados por la Iglesia católica, las diputaciones provinciales, los técnicos agrícolas y los medianos y grandes propietarios y sin que se produjese una iniciativa espontánea de los campesinos para su organización ${ }^{13}$. Como en otras zonas de la costa cantábrica no existió un foco campesino destacado adscrito a las ideologías de izquierda ${ }^{14}$. Los socialistas y los republicanos vascos no tuvieron un programa agrario específico ni, salvo excepciones, grupos organizados en el ámbito rural. El asociacionismo católico tenía, además, como uno de sus principales objetivos evitar la difusión de dichas ideologías y organizaciones por el agro vasco. La mayor parte de los autores que han estudiado esta cuestión coinciden en afirmar la debilidad del asociacionismo católico (hacia 1930, solo 37 de los noventa municipios guipuzcoanos y 45 de los 119 vizcaínos contaban con un sindicato agrario), el escaso dinamismo del movimiento y sus efectos limitados en el campo vasco, en contraposición con lo sucedido en otras regiones españolas, donde las sociedades agrarias, católicas o no, y en

sociedades genéricas y nueve asociaciones dedicadas a la ganadería. En Vizcaya contabilizaron seis sindicatos, veinticinco sociedades agrícolas y 44 dedicadas a la ganadería; Berriochoa (2014: 421) cifra en 32 el número de sindicatos miembros de la Federación Católica Agraria de Guipúzcoa en ese año, mientras que Muñiz (1927: 295-296) identifica veintisiete asociaciones.

9 En 1920 se creó la Federación Católica Agraria de Álava, manteniéndose el Sindicato Agrícola Alavés como organización más importante (Sanz Legaristi y Reboredo, 1985).

10 Andrés-Gallego (1984): 266-267.

11 Etxeberria (2015): 20. La memoria de 1920 de dicha organización afirmaba contar con 38 delegaciones en Vizcaya, tres en Álava (en los municipios cantábricos de Ayala, Arceniega y Lezama) y uno en Burgos, el Sindicato del Valle de Mena (Federación Católica Agraria de Vizcaya, 1921: 12).

12 Para el caso navarro, véase Majuelo y Pascual (1991) y Pejenaute (1989).

13 Delgado (2009): 49. No hay que descartar, sin embargo, la confluencia de intereses de grandes y pequeños propietarios, interesados todos en políticas arancelarias tendentes a mantener altos los precios de los productos agrícolas (Garrido, 2003: 50).

14 Cabo (2011). 
especial las cooperativas tuvieron una actuación más destacada, aunque irregular y espasmódica, en la modernización de la agricultura española.

Sorprende ese relativo eco, máxime en una región caracterizada por su alto nivel de práctica religiosa. Las explicaciones tienen que ir por otro lado. No vamos a insistir en aspectos de tipo político, institucional o empresarial, que además serían aplicables a toda España ${ }^{15}$. Pero conviene recordar que el asociacionismo agrario, el cooperativista en especial, se desarrolló de forma destacada en las zonas vinícolas, aceiteras y, en menor medida, trigueras. Tres modalidades de cultivo que no tenían gran extensión en nuestro caso. La preexistencia en torno a las tierras comunales o a comunidades de riego de redes sociales amplias también favorecieron el desarrollo societario. Como también lo hizo la existencia de un clima de confianza, y no de conflictividad política y social entre los propios campesinos, ya que el capital social y los mecanismos de cooperación generados en torno a dichas instituciones reducían los costes de transacción de la acción colectiva, al facilitar la difusión de la información y la actuación conjunta ${ }^{16}$. Pero, en la vertiente cantábrica vasca, el agua era un bien relativamente abundante $y$, al contrario, la propiedad comunal era un elemento que tenía un peso muy reducido después de la intensa desamortización civil producida en el siglo XIx. En cambio, su presencia o el recuerdo de su pérdida, era muy alto en Álava y en Navarra ${ }^{17}$. Las guerras civiles de aquella centuria, la propia división del tradicionalismo entre carlistas e integristas, la aparición de un nuevo movimiento como era el nacionalismo vasco no contribuyeron a cohesionar la comunidad campesina fuera de su entorno más próximo: la barriada o auzoa.

La ineficacia de la actuación de muchas de estos sindicatos y sus debilidades estructurales tampoco animaron a muchos campesinos a asociarse. No podemos olvidar, además, que el pequeño tamańo de las explotaciones vascas y la existencia de un mercado urbano próximo tampoco facilitaron dicho proceso asociativo ${ }^{18}$. Por último, el sindicalismo católico, conservador, mutualista y orientado a la ayuda técnica y profesional, no manifestó gran interés por algunas aspiraciones campesinas, en especial, por la pretensión de acceder a la propiedad de sus explotaciones. Al contrario, la Federación vizcaína contaba entre sus objetivos con «establecer los lazos de armonía entre el propietario y arrendatario $»^{19}$. Esta ausencia de atención específica a los arrendatarios,

\footnotetext{
15 Andrés-Gallego (1984): 256-257; Garrido (2007): 196, y Román (2015).

16 Beltrán Tapia (2012): 512 y 524.

17 Ruiz Urrestarazu (1985) y Majuelo y Pascual (1991).

18 Berriochoa (2014): 427.

19 Muñiz (1927): 120.
} 
junto con las expuestas en este párrafo, es probablemente la razón de su relativa escasa incidencia en el caso vasco, frente a zonas próximas, como Navarra o Castilla, donde abundaba el pequeño agricultor propietario, más interesado en la ayuda técnica que en la reivindicación social.

A partir de los años veinte del siglo xx apareció en la localidad guipuzcoana de Azpeitia una estructura societaria que buscaba trascender el mutualismo católico, focalizando su atención en el derecho de los arrendatarios a convertirse en propietarios y en una defensa más eficaz de la economía y el modo de vida agrario. Sería el germen de la Asociación de Campesinos Vascos, Euzko Nekazari Bazkuna (ENB). Este modelo encontró en el nacionalismo vasco de la época republicana un interlocutor privilegiado. La resistencia a tales iniciativas por parte de los grandes propietarios, vinculados con los partidos derechistas, incrementó el carácter político del nuevo sindicalismo agrario y provocó el recurso a un repertorio movilizador que, en el caso vasco, hasta entonces parecía haber sido patrimonio casi exclusivo de los grupos urbanos.

En un estudio anterior hemos discutido el contexto en el que surgió en Guipúzcoa ENB, matizando análisis que hacían hincapié en factores de tipo ideológico u organizativo-sindical para explicar la aparición de este nuevo fenómeno. Mi trabajo destacaba la actuación autónoma de los campesinos siguiendo la referencia azpeitiarra y su interacción con algunos elementos dirigentes del Partido Nacionalista Vasco (PNV) y del sindicato de la misma ideología, Solidaridad de Trabajadores Vascos (STV). Se trataba, por lo tanto, de un movimiento de autoafirmación agraria, pero que, al mismo tiempo, cubría un flanco descuidado hasta entonces por el nacionalismo vasco. En las páginas siguientes vamos a dedicar nuestra atención al trienio que se extiende entre febrero de 1933 y febrero de 1936.

Para ello analizaremos, por un lado, la actuación cotidiana de la nueva organización y, por el otro, las relaciones entre ENB, el PNV y STV, extendiendo además el campo de estudio a la provincia de Vizcaya, donde en 1935 se formó Euzko Nekazari Alkartasuna (Solidaridad de Campesinos Vascos). Buscamos, asimismo, confirmar o desechar la hipótesis, apuntada en investigaciones anteriores, de que fue el trabajo autónomo realizado por los dirigentes nekazaris lo que permitió atraer a un buen número de campesinos, arrendatarios mayormente, que, o bien habían permanecido alejados de las cuestiones políticas o bien se habían alineado hasta entonces en las filas tradicionalistas ${ }^{20}$.

20 La mayor parte de los movimientos agraristas europeos que tuvieron éxito se lo debieron a la implicación del campesino en su organización y dirección (Lynch, 2009: 135). 


\section{EL DESARROLLO DEL SINDICALISMO AGRARIO AUTÓNOMO EN GUIPÚZCOA}

Tras el final del proceso constituyente de Euzko Nekazari Bazkuna en febrero de 1933, los primeros meses del sindicato fueron de gran actividad, combinándose las reuniones locales para la constitución de agrupaciones con los mítines que buscaban una asistencia masiva. No es sencillo discernir los ejes sobre los que se produjo la difusión del movimiento agrarista. Las reuniones para constituir agrupaciones o celebrar actos de propaganda se realizaron tanto en las sedes sociales del nacionalismo vasco, como en espacios propios de la sociabilidad campesina, aprovechando los días de feria y los momentos relacionados con el ámbito festivo. Los temas tratados en estas asambleas no diferían mucho de un orador a otro: el principal era la importancia de la organización de los campesinos y la virtud taumatúrgica de la asociación. El sacerdote Policarpo Larrańaga, uno de sus principales propagandistas, lo expresó claramente en una charla en Mondragón: si todos los baserritarras (los caseros) se asociaban, como habían hecho los trabajadores industriales, era factible conseguir grandes progresos, pero el campesino aislado no podía hacer nada ${ }^{21}$. Del mismo modo, la asociación campesina sería un antídoto para que los caciques se contuviesen a la hora de exigir a los campesinos que les cediesen su voto. De esta forma, los baserritarras podrían elegir a los concejales o diputados que considerasen oportuno. Otro de los temas recurrentes en mítines y artículos era la dignificación del campesinado, tratando de presentar a los campesinos como arquitectos de su propio destino y no como agentes pasivos, víctimas de la historia. Los conferenciantes, campesinos en su mayoría o procedentes del medio periurbano, hacían abstracción del apoyo recibido desde el mundo urbano e insistieron en la importancia de la autoorganización campesina como elemento decisivo para el éxito de la iniciativa. En esta primera etapa, todavía con un Gobierno de izquierdas en España, no faltaron las criticas a la política socialista sobre el tema agrario, denunciando que su resultado sería la desaparición de la religión y de la lengua vasca y, siguiendo el modelo soviético, el paso de las propiedades agrarias a manos del Estado, la pérdida de la autonomía campesina y el hambre ${ }^{22}$.

En las reuniones constitutivas de las agrupaciones locales se producía la lectura del reglamento de funcionamiento y, tras su aprobación, se efectuaba la inscripción de los socios. Estos tenían que pagar una cuota de dos reales mensuales, que les daba derecho a utilizar la asesoría legal instalada en San

21 «Arrasate», Euzkadi, 18-2-1933.

22 «Lasarte», Euzkadi, 21-4-1933; y en el mismo «Motriko», 26-8-1933. 
Sebastián. Por último, se producía la elección de las juntas directivas que recaían generalmente en pequeños campesinos arrendatarios, muchos de ellos afiliados al PNV y/o a STV. La culminación de este primer desarrollo fue la constitución definitiva de la asociación, en agosto de 1933, en una asamblea a la que acudieron representantes de veintisiete localidades y de un total aproximado de 2000 afiliados $^{23}$.

Con anterioridad, en mayo, se produjo la adhesión de Euzko Nekazari Bazkuna a la Confederación Nacional de Solidaridad de Trabajadores Vascos como organización autónoma relacionada directamente con la directiva del sindicato, lo que le permitía mantener un funcionamiento propio y una línea de actuación separada de la del sindicato. Las relaciones entre las dos organizaciones fue motivo de debate en los primeros meses del año. Un escrito en el semanario Argia sintetizaba los vínculos entre ambos entidades ${ }^{24}$. ENB era una de las ramas del árbol sindical. Los baserritarras no debían actuar de forma subordinada al sindicato industrial, sino bajo su protección, discutiendo con total libertad las cuestiones propias de los campesinos. No faltaron, por otra parte, signos de complicidad entre ambas organizaciones. Además del uso sistemático de los locales de Solidaridad para celebrar las primeras reuniones de ENB, esa proximidad es palpable en hechos como el producido en la localidad de Zarautz, en octubre de 1933, cuando, en solidaridad con los sindicalistas nacionalistas vascos del sector del mueble en huelga, los baserritarras afiliados a ENB se negaron a proporcionar el suministro de leche habitual a la población, contribuyendo de esta forma al triunfo de los huelguistas ${ }^{25}$.

El año 1933 fue pródigo en acontecimientos en el ámbito político. El primero de ellos fue las elecciones municipales en aquellos ayuntamientos que habían sido elegidos por el artículo 29 en abril de 1931. Dichos comicios conocieron un doble fenómeno complementario: el fuerte impulso que consiguieron las candidaturas cobijadas bajo el paraguas del nacionalismo vasco ${ }^{26}$

23 El archivo de Euzko Nekazari Bazkuna desapareció en septiembre de 1936 tras la ocupación de San Sebastián por parte de las tropas sublevadas, por lo que las fuentes fundamentales de nuestra investigación han sido las noticias publicadas en la prensa.

24 «Basarritar, alkartu», Argia, 2-3-1933.

25 "Oporketa ondoren», Euzkadi, 6-10-1933.

26 Como es conocido, el PNV se presentó el año 1931 en coalición con otros grupos derechistas, con la Comunión Tradicionalista en particular, y por lo tanto, no es posible comparar los datos de los comicios de 1931 con los de 1933. En el periodo restauracionista, los mejores resultados del PNV se produjeron en las zonas urbanas. 
y, en segundo lugar, la presentación en varias localidades de candidatos, apoyados por el PNV, pero que se definieron específicamente como agrarios y miembros de ENB (Azkoitia, Azpeitia, Elgoibar y Antzuola cuando menos). No se ha subrayado de forma suficiente este hecho, que muestra la clara vocación política del sindicato agrario, pese a sus protestas de apoliticismo, pero que era lógica, en la medida en que el control de los ayuntamientos era central a la hora de aplicar o bloquear las demandas campesinas en los presupuestos municipales y en las diferentes disposiciones y censos necesarios para llevar a la práctica la reforma agraria ${ }^{27}$. Los peneuvistas fueron excluidos sistemáticamente de las comisiones gestoras que gobernaron las diputaciones provinciales durante el periodo republicano, lo que dificultó el recurso a dichas instituciones para obtener apoyo a las medidas propuestas por los campesinos pequeños propietarios o arrendatarios. Tampoco tenían presencia en los consejos de las dos importantes cajas de ahorro existentes en la provincia.

En septiembre de 1933, dos de los principales dirigentes nekazaris, Lino Lazcano (obrero mixto que combinaba el trabajo industrial con el de su caserío en arriendo) y Gabino Murua (casero propietario), fueron elegidos, junto con otras trece personas, como representantes guipuzcoanos en la Asamblea Nacional del Partido Nacionalista Vasco. ENB contó con el apoyo del semanario Argia y de la página semanal dedicada a cuestiones agrarias por el periódico filonacionalista El Día, más la cobertura ofrecida por el portavoz oficial del PNV, el diario Euzkadi. Parece evidente la complicidad y buena relación entre el sindicato agrario y el nacionalismo vasco. No parece, por lo tanto, que hubiese grandes diferencias políticas o ideológicas entre los impulsores de la organización y la entidad más destacada del nacionalismo vasco, aún manteniendo su respectiva autonomía.

ENB difundió un manifiesto anunciando su petición de voto afirmativo ante el referéndum del proyecto de estatuto de autonomía para el País Vasco elaborado por las gestoras provinciales y que sería votado el día 5 de noviembre de $1933^{28}$. La razón era evidente a ojos de sus dirigentes: el proyecto de estatuto prometía en su articulado llevar a la práctica todos los objetivos por los que se había creado Euzko Nekazari Bazkuna (fortalecer la vida en el caserío, facilitar la compra del mismo por parte de los arrendatarios, intermediar entre propietarios y renteros, posibilitar la permanencia de los campesinos en sus caseríos declarando la indivisibilidad de la propiedad campesina, reducir la presión fiscal sobre los productos agrícolas, roturar los terrenos incultos, fomentar la creación de seguros agrícolas

27 Cabo (2009): 383.

28 «Gipuzkoa’ko nekazariak», Euzkadi, 26-10-1933. 
y de cooperativas, etcétera). ENB animaba a todos los campesinos, no solo a depositar su voto afirmativo, sino también a movilizar a sus vecinos y amistades en la misma dirección.

No se produjo idéntica manifestación con ocasión de las elecciones a Cortes que se celebraron el día 19 de ese mismo mes, pero los resultados mostraron una clara correlación entre la existencia de secciones locales de ENB y la victoria nacionalista. Los nacionalistas obtuvieron el 45,13\% de los votos en las elecciones legislativas, triunfando en 75 de los 89 municipios guipuzcoanos. En la zona rural, el PNV obtuvo la victoria en veintidós de las veintisiete localidades que la componían, elevando su porcentaje de voto hasta el $62,28 \%{ }^{29}$. De hecho, el nacionalismo vasco venció en las veintisiete poblaciones que contaban en aquel momento con una agrupación local de nekazaris. La victoria nacionalista también se tradujo en una nuevo impulso para la asociación agraria guipuzcoana, que se plasmó en el aumento del número de afiliados, pero también en una mayor pluralidad de actividades, entre las que se incluyeron las de tipo mutualista. El sindicato consiguió, además, un amplio triunfo en las elecciones de los representantes de los caseros arrendatarios del Jurado Mixto de la Propiedad Rústica de Guipúzcoa (diciembre de 1933), demostrando así la fortaleza que había adquirido en muy pocos meses. Cuando se celebró su primera asamblea ordinaria, el 11 de marzo de 1934, el panorama que presentaba la organización era ciertamente brillante, 51 secciones locales y 4200 afiliados. Dos años más tarde, en la tercera asamblea anual en marzo de 1936, el sindicato contaba con 66 secciones locales y 5250 socios $^{30}$.

Si en un primer momento la dirección del sindicato estuvo encabezada por un casero donostiarra, Eusebio Goñi, su secretario general, a partir de una fecha indeterminada, pero que podemos fijar a mediados de 1934, Goñi desapareció de la escena pública para ser sustituido por Lazcano, Murua y el sacerdote Larrañaga, verdadero triunvirato de ENB en el segundo bienio republicano. En septiembre de ese año, Gabino Murua era presentado como secretario general de los nekazaris de Gipuzkoa, colaborando estrechamente con el joven abogado José María de Lojendio, encargado de la asesoría jurídica ${ }^{31}$.

29 Rodríguez Ranz (1994): 408 y 480-486.

30 "Gipuzkoa'ko Eusko Nekazarien 1935'ko gora-berak», Argia, 29-3-1936 (Díaz Noci, 2001).

31 Lojendio, procedente de Acción Católica, se sumó al bando franquista en 1936, y aunque no alcanzó la notoriedad de alguno de sus hermanos, fue elegido presidente de la Academia de la Lengua Vasca en 1964. 


\section{LA ACTUACIÓN PRÁCTICA DEL SINDICALISMO NEKAZARI}

Las actividades desarrolladas por el societarismo agrarista de signo nacionalista abarcaron diferentes campos. Por una parte, la propaganda y la organización (los aspectos más visibles de su actuación). También las ayudas a los damnificados por catástrofes naturales. Las graves inundaciones que se produjeron en Guipúzcoa el 16 de junio de 1933, que causaron cinco muertos, un desaparecido y multitud de daños en la comarca de San Sebastián de forma especial, permitieron mostrar la fortaleza de la nueva organización y el apoyo que tenía del Partido Nacionalista Vasco. La Junta de Socorros de esta organización se movilizó para allegar muebles, ropas, enseres y comestibles a unas doscientas familias y, en algunos casos, se donaron yuntas de bueyes para que los damnificados pudiesen reanudar sus actividades. Como era relativamente habitual en la época, o así lo hacía al menos el PNV, la entrega de las ayudas sirvió como acto propagandista. El presidente de ENB, Eusebio Goñi, «entusiasta propagandista solidario y patriota», representó a la Junta de Socorros del PNV en dichos actos ${ }^{32}$.

Euzko Nekazari Bazkuna y, en menor medida, Euzko Nekazari Alkartasuna, no se limitaron a la labor proselitista. Buscaron la regulación de los mercados, la protección arancelaria de sus productos y el apoyo a los baserritarras ante la enfermedad, los accidentes y las catástrofes naturales. También reclamaron la mejora de las condiciones de arrendamiento, el reconocimiento del derecho a adquirir las tierras arrendadas y asumieron la defensa de los baserritarras frente a los propietarios. Lino Lazkano, el presidente de ENB, animó a los arrendatarios a acudir a la asociación con más frecuencia, «a exponer allí la queja más insignificante, siempre que sea justa, de un propietario tirano o cosa similar, para que la Sociedad recurra al Jurado Mixto, del que él mismo es miembro integrante, donde se mitiga la furia de esos jauntxos (señores) que parecen indomables" ${ }^{33}$. Trataron asimismo una cuestión que estaba empezando a generalizarse: la tendencia de algunos propietarios de instalar en los terrenos de su propiedad plantaciones forestales (pinos de forma habitual) que reducían el espacio que el arrendatario podía utilizar para cultivos o como pastos, amén de agotar los nutrientes del suelo en la mayor parte de los casos.

Otro de los campos de actuación sindical fue el de la gestión ante las autoridades municipales o provinciales, en una doble dirección. Por una parte, intentando que se dejasen sin efecto medidas que afectaban a los campesinos, supuestamente de forma injusta (excesivo rigor en los análisis de la calidad de

32 «De las inundaciones de Gipuzkoa», Euzkadi, 13-10-1933.

33 «Bergara», Euzkadi, 19-9-1934. 
los alimentos, creación o eliminación de impuestos específicos sobre el campesinado, como la tasa establecida en Vizcaya en 1935 a los carros tirados por ganado vacuno u asnal). Por otra, solicitando mejoras en las infraestructuras: establecimiento de líneas telefónicas en zonas rurales, construcción de carreteras que comunicasen los barrios más alejados con los núcleos urbanos, establecimiento de escuelas, reparto de los presupuestos festivos de forma equitativa ente las zonas urbanas y las rurales, etc. La secretaria acompańó, por último, físicamente a numerosos campesinos en las gestiones que tenían que realizar en los centros oficiales de la capital. Esta labor de intermediación reforzó la legitimidad y prestigio de los líderes nekazaris ${ }^{34}$.

Uno de las cuestiones recurrentes en el discurso y en la práctica de los nekazaris fue la cuestión de las carnicerías. Los campesinos negociaban con tratantes y matarifes de forma individual la venta de sus reses y eran constante, por lo que se ve, las quejas de los ganaderos, tanto por la comisión en especie que se llevaban los matarifes al sacrificar los animales, como por el precio de venta de estos últimos ${ }^{35}$. Fueron frecuentes las propuestas realizadas a la dirección del sindicato para que habilitase fórmulas que posibilitasen la venta directa de los productos cárnicos. Lo que demostraba, a los ojos de este, la voluntad de los asociados de gestionar sus propios recursos ${ }^{36}$. Se trataba, sin embargo, de un problema arduo que necesitaba un estudio y unas condiciones previas para evitar su fracaso. De esta forma era necesario que cada agrupación dispuesta a implantar su propia carnicería contase con un grupo de al menos cincuenta socios dispuestos a abonar una cantidad inicial de cien pesetas cada uno. Tras fijar precios y cantidad de animales a sacrificar, había que decidir previamente el destino de los distintos tipos de carne y elegir un matarife. Una vez reunidas estas condiciones, las secciones locales debían ponerse en contacto con el secretariado provincial para que este proporcionase el marco legal a la cooperativa y vehiculase las ayudas que las leyes disponían para estas instituciones. Otra propuesta, más sencilla pero menos ambiciosa, consistía en recurrir a las autoridades municipales para que ejerciesen un mayor control sobre los empleados de los mataderos. El año 1935 vio como se abrían cuatro carnicerías propiedad de agrupaciones locales.

En el caso vizcaíno, ya antes de la propia creación de Euzko Nekazari Alkartasuna, los expertos al servicio de la Comisión Técnica del BBB mostraron su predilección por la formación de los caseros, un problema que era considerado como una de las principales dificultades de la economía campesina.

\footnotetext{
34 Lynch (2009): 155.

35 «Elgoibar», Euzkadi, 27-9-1933.

36 «Gizarte-arazoak», Argia, 23-9-1933.
} 
Una de las formas de solventar dicha cuestión era a través de cursillos teórico-prácticos en los que un técnico mostraba a un grupo de campesinos diversos métodos para mejorar la producción, en especial de la fruticultura. Este sector estaba experimentando un importante crecimiento en los últimos años. La presencia de estos expertos, los ingenieros agrícolas Joaquín Olaizola y Jesús Olascoaga y el perito agrícola Antonio Laburu, es otra novedad frente al caso guipuzcoano, donde los titulados agrícolas no tuvieron, que sepamos, ningún papel en la actuación sindical.

\section{EUZKO NEKAZARI ALKARTASUNA, LAS LIMITACIONES DE UN PROCESO DESDE ARRIBA EN VIZCAYA}

El tratamiento de la cuestión agraria por parte del nacionalismo vasco en el territorio de Vizcaya respondió a una dinámica específica. Una de las razones de dicho hecho estriba en el más rápido y mayor desarrollo que el movimiento creado por Sabino Arana había tenido en su tierra natal. En las elecciones de 1933, los candidatos nacionalistas del distrito de Vizcaya-provincia obtuvieron en torno a 80000 votos, los derechistas unos 40000 votos y las izquierdas 18000 sufragios. Dos años más tarde, en la primera vuelta los nacionalistas, que intentaron el copo votando a tres candidatos, obtuvieron 70000 votos, por 46000 los derechistas y 19000 las izquierdas. Por ello era menos necesaria una atención específica a los problemas del agro vizcaíno, al menos como forma de proselitismo político ${ }^{37}$. La fortaleza y solidez del sindicato nacionalista, Solidaridad de Trabajadores Vascos, eran también mucho mayores en este territorio. Una segunda razón está relacionada con el enorme peso que la capital vizcaína, Bilbao, tuvo en la génesis y expansión del nacionalismo vasco. El ruralismo que caracterizó al primer nacionalismo y su defensa del mundo campesino frente a las críticas desarrolladas por parte de la prensa vizcaína estaban complementados con un discurso y una realidad urbana que priorizaba lo que estaba sucediendo en las ciudades. La simpatía del PNV hacia el caserío y los caseros estaba acompañado de un indisimulado sentimiento de superioridad de los urbanitas sobre los campesinos y de una intensa desconfianza hacia la capacidad de actuación campesina, necesitada del tutelaje de los dirigentes procedentes de la capital, un pensamiento que estaba extendido entre la mayor parte de las fuerzas políticas, desde la extrema derecha a la extrema izquierda comunista ${ }^{38}$. Una tercera razón, que debe

37 http://www.euskadi.eus/emaitzak/republica/republica_c.htm [consultado el 20-9-1936].

38 Berriochoa (2014). 
estudiarse de forma específica para poderla confirmar, es la presencia en las filas nacionalistas vizcaínas de sectores de clase media y alta que no veían necesariamente con buenos ojos la posibilidad de la expropiación de la propiedad, siquiera con indemnización ${ }^{39}$. No obstante, no hemos encontrado entre los principales propietarios rurales de la provincia a elementos destacados de las diferentes organizaciones nacionalistas vascas. El listado elaborado por los geógrafos Luisa Utanda y Francisco Feo con los 138 poseedores de más de veinticinco hectáreas utilizando los fondos del Registro de la Propiedad expropiable recopilados en 1933, apenas contiene media docena de nombres de seguidores de Sabino Arana. Los más conocidos eran Anacleto Ortueta, fundador de Acción Nacionalista Vasca, y Carlos Solano Adán de Yarza, uno de los pocos miembros de la aristocracia vasca que se sumó al PNV ${ }^{40}$.

El sacerdote Policarpo Larrañaga, por su parte, nos señala otras razones para explicar la evolución en el tratamiento de la cuestión agraria en Vizcaya por parte del nacionalismo vasco ${ }^{41}$. En primer lugar, la amplia implantación del PNV en la provincia hacía innecesaria una nueva asociación «apolítica» para articular al campesinado afín. El miedo a un hipotético movimiento socialista que pudiese infiltrarse en esa organización también frenó esa posibilidad ${ }^{42}$. La diferente estructura de la propiedad en Guipúzcoa y Vizcaya, el mayor número de pequeños propietarios en Vizcaya y una relativa menor presencia de los arrendatarios haría más complicado conseguir la movilización de estos últimos ${ }^{43}$.

39 Hay que recordar en este sentido que la petición de la propiedad por parte de los arrendatarios provocó, también en los casos gallego o catalán, una fractura o, cuando menos, el tensionamiento de la sociedad local (Pomés, 1995; Mayayo, 1995; Fernández Prieto, 1997, y Prada, 2006: 507).

40 Utanda y Feo (1996).

41 «Euzko Nekazariak». Archivo Histórico del Gobierno Vasco. Fondo del Departamento de Presidencia. Secretaría General (Bilbao, Barcelona, París). Prensa y propaganda. Informes. Legajo 09, exp. 01.

42 Aunque hay alguna localidad rural con cierta presencia republicana, el voto de izquierdas en la zona rural vizcaína fue mínimo. En las elecciones de 1936 la candidatura del Frente Popular obtuvo en la primera vuelta en el distrito de Vizcaya-Provincia (que incluía varias poblaciones industriales y mineras) el 14,2\% de los votos.

43 Según los datos aportados por la diputación a Gregorio de Balparda (1935:46) existían en dicho territorio 19216 fincas de labranza, de las que 7158 eran cultivadas por sus propietarios y 12058 por arrendadores. El número de caseríos sencillos, habitados por una sola familia era de 9968 y el de dobles de 8330. 913 fincas estaban constituidas por lotes de tierra no adscritas a un caserío. Un año antes Ibañez y Vidaurrazaga (1934: 96-97) situaban, sin citar sus fuentes, la proporción de propietarios en el $37,15 \%$, el de arrendatarios en el 65,25\% y el número de caseríos en 14133. 
El último factor mencionado por Larrañaga sería la influencia del semanario Ekin. Este periódico filonacionalista estaba editado por la asociación de sacerdotes Jaungoiko-Zale, y pese a la existencia de algunos artículos defendiendo la organización autónoma del campesinado, la mayor parte de los textos, en especial los escritos por el principal articulista sobre temas agrarios de la publicación, Kepa ${ }^{44}$, defendieron la utilidad de la Federación Católico Agraria de Vizcaya ${ }^{45}$. En esta organización, como en la Federación de Ganaderos y Labradores de Vizcaya ${ }^{46}$, abundaban los nacionalistas. De hecho, en mayo de 1932 la Federación Católico Agraria celebró un acto social en Mungia en el que participó, entre otros, Vicente Echezarraga Zidorra, conocido nacionalista de Zeanuri, y el coro del batzoki local ${ }^{47}$.

En cualquier caso, la Federación Católica Agraria de Vizcaya estaba presidida por el político dinástico Alejandro Gaytán de Ayala (vicepresidente de la Diputación de Vizcaya en 1929), un miembro de la aristocracia con importantes propiedades en el este de la provincia ${ }^{48}$. La Federación, que había mostrado su apoyo al proyecto de estatuto de autonomía vasco de 1931, manifestó en julio de ese mismo sus recelos ante el sistema republicano si no se producía «el restablecimiento del imperio de la ley, el mantenimiento a toda costa del orden público y el respeto a la propiedad, de la que nadie debe ser desposeído sin una previa y justa indemnización » ${ }^{49}$. Casi dos años más tarde, la Federación envío otro escrito al Gobierno espańol, en nombre de los supuestamente 1500 labradores adheridos, solicitando a la Dirección General de la Reforma Agraria que no se aplicase en esta provincia el apartado décimo de la base quinta de la Ley de la Reforma Agraria $^{50}$. Dicho apartado permitía la expropiación de las fincas situadas «a distancia menor de dos kilómetros del casco de los pueblos de menos de 25000 habitantes de derecho, cuando su propietario posea en el

44 Desconocemos la persona que se encontraba bajo dicho pseudónimo. Puede tratarse de Pedro Urquidi, un técnico de la Diputación Provincial de Vizcaya.

45 «Lur langilleak itxartu», Ekin 20, 18-6-1932.

46 Hay cierta confusión entre la organización católica y la federación ganadera. Formalmente eran dos organizaciones diferentes, aunque no hemos encontrado información suficiente para detallar las especificidades de cada asociación.

47 «El grandioso acto social de Mungia», Euzkadi, 19-5-1932. La sección local de Munguia había sido creada en 1914 y su primer presidente fue Benito Gamboa, que también lo era de la Junta Municipal del PNV (Delgado, 2009: 50).

48 Gaytan de Ayala, tras ocultarse durante varios meses en un caserío a causa de la Guerra Civil, pudo huir a la zona sublevada (Juaristi, 2011: 231).

49 "Ante la crisis monetaria y de la economía nacional», $A B C, 31-7-1931$.

50 "Un escrito de los propietarios de Vizcaya», La Época, 20-1-1933. 
término municipal fincas cuya renta catastral exceda de la cantidad de 1000 pesetas, siempre que no estén cultivadas directamente por sus dueños». La Federación, por lo tanto, se alineaba con los grandes y medianos propietarios, ya que dicha disposición les podía afectar directamente.

La preocupación del nacionalismo vizcaíno por la articulación de los sectores sociales rurales se incrementó según avanzaban los años republicanos y se manifestó además en la conciencia de que era necesaria la mejora de las condiciones de orden material de dicho espacio para que pudiera producirse la libertad del pueblo vasco e incluso su propia subsistencia como entidad diferenciada $^{51}$, pero fue un proceso lento. El Secretariado General Vasco (el organismo que se ocupaba de la gestión cotidiana del PNV en Vizcaya) creó diversas comisiones, como la Junta Pro Caserío Vasco (1932), pero no parece que sus actividades fuesen muy efectivas, ni muy duradera en el tiempo. Se produjo, además, un respaldo a las tesis del abogado nacionalista Tomás Egidazu, contrarias a la posibilidad de que la Ley de Reforma Agraria se aplicase en el caso vasco ${ }^{52}$. Una ley que era considerada por Egidazu como estatista y que impediría la posibilidad de que el campesino pudiese convertirse en propietario de la tierra que cultivaba. Para conseguir esa pretensión, la fórmula que propugnaba el sacerdote Alberto Onaindia era la de la compra mediante la ayuda de los poderes públicos y, en particular, de las cajas de ahorro. Para los portavoces del nacionalismo vasco en Vizcaya no existía, por lo tanto, problema agrario o, mejor dicho, no existiría con la autonomía. La agricultura podía ser una de las bases fundamentales de la economía y la paz social vasca «a poca atención que se le preste desde las esferas directrices de la legislación nacional, atención que hoy y siempre se le viene negando por carencia de facultades que se seguirían del reconocimiento de nuestra propia personalidad $\aleph^{53}$.

Hubo que esperar hasta enero de 1934 para que se iniciase en Vizcaya una actividad encaminada a la constitución de la Solidaridad de Campesinos Vascos. El día 12 de ese mes se publicó en el diario Euzkadi el manifiesto de presentación de la comisión organizadora. Aunque el apartado sobre la finalidad de la organización recogía prácticamente con las mismas palabras el articulado aprobado un año antes por Euzko Nekazari Bazkuna, había algunas diferencias significativas. La primera es la ausencia de referencia alguna a ENB. De hecho, la única organización mencionada en el texto era Solidaridad de Trabajadores Vascos, aunque no se expresase ningún tipo de vinculación entre el

51 "Cuestiones sociales», Euzkadi, 21-4-1932.

52 Egidazu (1932).

53 "Cuestiones sociales», Euzkadi, 21-4-1932. 
sindicato obrero y el campesino. La segunda es que el texto se presentó únicamente en castellano, siendo el euskera la lengua habitual y casi única de la gran mayoría de los campesinos vizcaínos. Ni siquiera se mencionaba el nombre oficial de la nueva organización, Solidaridad de Campesinos Vascos, Euzko Nekazari Alkartasuna (ENA). La tercera es la radicalidad de los términos utilizados en el escrito:

Tú, campesino bizkaino, continúas abandonado a tu suerte, luchando en la soledad del campo contra toda clase de enemigos que se han conjurado contra ti: las Corporaciones oficiales, que no se acuerdan de ti más que para sangrarte coa injustos impuestos; la Banca y la usura, que no hacen más que explotar tu ahorro o tu indigencia, y, sobre todo, el capitalismo rural, que se ha apropiado de más de la mitad del agro bizkaino, creando esa plaga de grandes propietarios que, salvo honrosas excepciones, caciquilmente, inhumanamente, anticristianamente, quieren constituirse en dioses feudales de los pobres inquilinos que han caído en sus garras. ¡Y tú, campesino, digno hijo de la raza más noble y libre del mundo, el más auténtico representante de nuestra amada patria euskadiana, no puedes consentir esto ${ }^{54}$.

Una primera conclusión era evidente: los autores del escrito no eran campesinos. Ningún miembro del agro vizcaíno se hubiese autodefinido a si mismo con los términos utilizados en las última frase del párrafo que recogemos; tampoco hubiese utilizado expresiones como "capitalismo rural» desconocidas para él; sabía que la única forma de acceder a otros campesinos, salvo en las Encartaciones o en la Margen Izquierda, era utilizando el euskera y tenía que conocer, siquiera de forma indirecta, la aparición del sindicalismo nekazari en Guipúzcoa. De hecho, el modelo organizativo propugnado en el texto era el de ENB. Desconocemos la razón que llevó a no mencionar dicha organización en el manifiesto. No se incluían, por otra parte, en el texto, ni una dirección de contacto, ni los nombres de los miembros de la comisión organizadora. En estas condiciones, el "profundo y rápido triunfo» que se auguraba a la iniciativa no era más que una voluntariosa declaración de intenciones.

Afortunadamente Darío Ansel ha podido reconstruir los pasos que llevaron a la publicación de dicho manifiesto ${ }^{55}$. El texto fue la confluencia de dos iniciativas: la creación en el seno del Bizkai Buru Batzar (BBB) —el Consejo Regional de Vizcaya del PNV— de un departamento de Agricultura (marzo

"Al campesino bizkaino», Euzkadi, 12-1-1934

Ansel (2011): 22-23. 
de 1933) y la aprobación en el congreso de Vitoria de STV de un programa agrario (mayo de 1933), y aunque los documentos que se conservan dejan en manos del BBB, a propuesta de Policarpo Larrañaga, la decisión de crear Solidaridad de Campesinos Vascos, parece patente que la filosofía del texto estaba más próxima a una STV en proceso de radicalización, de «evolución sindicalista». El propio nombre utilizado «Solidaridad» y el lema «unión campesina y fraternidad vasca» (traslación del lema solidario «unión obrera y fraternidad vasca») así lo daban a entender.

Hay que valorar, no obstante, si esa supuesta radicalidad solidaria era compartida por todos los miembros de la comisión, por el PNV y, sobre todo, por el campesinado vizcaíno, que no mostró excesiva celeridad para integrarse en la nueva asociación. El portavoz periodístico del nacionalismo vasco hizo abstracción de que su afirmación de que "con la implantación en Bizkaya de Euzko-Nekazari-Alkartasuna, quedan atendidos los intereses profesionales de nuestros campesinos, que hasta la fecha venían constituyendo la única clase profesional que no seguía, y no por falta de deseo, a sus hermanos los solidarios vascos $»^{56}$ era, como hemos visto inexacta, ya que existía un amplio tejido asociativo agrario y profesional que no tenía ninguna intención de desaparecer por la mera creación de ENA y, de hecho, el propio diario Euzkadi se hacía eco de sus actividades. Este periódico, además, dedicó mucho más espacio a descalificar la falta de atención de las instituciones públicas a las cuestiones agrarias o un improbable agrarismo socialista que a criticar a los muy reales propietarios rurales ${ }^{57}$.

Un mes más tarde, en febrero de 1934, se anunciaba la celebración del primer mitin de la nueva organización. Se trataba en un acto en Markina, una localidad cercana a la muga con Guipúzcoa y alejada de los centros neurálgicos de la provincia ${ }^{58}$. Los oradores fueron dos campesinos guipuzcoanos, Eusebio Goñi y Lino Lazkano, y el que se presentaba como presidente de la asociación, Pedro Ormaechea, miembro destacado de Solidaridad de Trabajadores Vascos. Mientras Lazkano denunció la actitud de los caciques que habían esclavizado a los baserritarras guipuzcoanos, Goñi se limitó a explicar de forma somera los principales puntos del programa de ENB. Ormaechea, por su parte, anunció que los baserritarras recibirían la ayuda incondicional de Solidaridad de Trabajadores Vascos. El acto concluyo con el nombramiento de la comisión organizadora de la Agrupación de Campesinos Vascos de Markina y Jemein. Las noticias escasearon los meses siguientes; hubo que esperar

56 «Una nueva organización», Euzkadi, 13-1-1934.

57 «Solidaridad y el Agro», Euzkadi, 16-5-1934.

58 Sobre la historia de la localidad en los años republicanos, Juaristi (2011). 
hasta abril y mayo para que se diese cuenta de la constitución de sendas agrupaciones en las pequeñas poblaciones de Kortezubi, Ajangiz y Arteaga, en la comarca de Gernika y no muy lejos de Markina. Desconocemos la razón por la que el llamamiento a la organización campesina solo tuviese eco en los partidos judiciales de Markina y Gernika. Existe un rasgo distintivo: una mayor proporción de campesinos propietarios en dichos distritos, alcanzándose el $42,55 \%$ del total en el distrito de Markina y un 45,25\% en el de Gernika, frente a un $32 \%$ del distrito de Durango, con el que compartían situación económica, homogeneidad cultural, etc., pero no nos atrevemos afirmar que esa fuese la razón fundamental para que el movimiento nekazari se iniciase en esa zona del territorio. En cualquier caso, la iniciativa no fue acogida con entusiasmo, ni por los grupos organizados del nacionalismo vasco, ni por el propio campesinado vizcaíno.

Además de las razones aducidas en la introducción de este apartado, cabe apuntar algunas más, para explicar ese retraimiento. Se han comentado en diversos trabajos las numerosas referencias de la publicística nacionalista vasca al tema rural, definido como eje de la nación vasca y al modelo de sociedad propugnado por el nacionalismo vasco. $\mathrm{Ni}$ esas referencias fueron tan abundantes, salvo en la iconografía, ni tal hecho convirtió necesariamente al campesinado en un receptor favorable de los mensajes del nacionalismo vasco. Por una parte, existía una ya larga tradición de vinculación entre el campesinado parcelario vasco y las diferentes vertientes del carlismo. En segundo lugar, el control y la presión de los propietarios rurales y de los notables locales, fuesen carlistas o liberales, dificultaron la actuación autónoma de los campesinos. Hay, además, un tercer factor que pocas veces se ha tenido en cuenta: la desconfianza campesina hacia las propuestas sociopolíticas provenientes del ámbito urbano y el nacionalismo vasco, por muy neorruralista que fuese, eran una ideología y un partido político urbanos. La labor de los impulsores del sindicalismo nekazari tuvo, por lo tanto, que hacer frente a numerosos obstáculos. Por ello fueron constantes las apelaciones a los caseros a crear estructuras societarias o a integrarse en las ya formadas, haciendo abstracción del origen foráneo de la propuesta e insistiendo en que el núcleo original de la nueva organización estaba compuesto por los propios campesinos ${ }^{59}$.

La iniciativa recibió un impulso renovado a comienzos de 1935. Se constituyó una nueva comisión compuesta por dos delegados de Solidaridad de Trabajadores Vascos, dos técnicos agrícolas y un delegado del BBB. Dada la situación de represión que se vivía como consecuencia del intento revolucionario

59 Una síntesis de estas cuestiones, «Euzko Nekazari Alkartasuna eta Euzko Baserrijak», Euzkadi, 3-6-1934. 
de octubre de 1934, la opción en este caso fue organizar una serie de cursillos de prácticas agrícolas con el apoyo de varios ingenieros agrónomos, demostrando los beneficios de la formación específica y las ventajas de estar asociados. El periódico Euzkadi también dedicó una mayor atención a las cuestiones agrarias a través de la página "Labor social. Página agrícola», y en la misma, junto con artículos orientados a la mejora de la producción agrícola, tampoco faltaron textos criticando la extensión que había adquirido la figura del campesinado arrendatario. Este hecho se vinculaba a la pérdida de los Fueros. Un miembro de la nueva comisión organizadora, que firmaba sus escritos como Dionisio de Arantzamendi, sintetizó la cuestión de forma lapidaria:

Los arrendatarios, salvo honrosas excepciones, han sido tratados por sus amos como seres pertenecientes a una casta inferior, sometiéndola a condiciones e imposiciones reñidas con la dignidad humana [...]. No faltan quienes han afirmado que no hay cuestión social en el campo vasco y que nuestro campesino vive alegre y feliz. Estos tales no conocen el agro nuestro más que a través de las ventanas de los vehículos en que han recorrido el país ${ }^{60}$.

El mitin que se celebró en Gernika el 13 de mayo, día de mercado, marcó el inicio de la expansión de los nekazaris en Vizcaya, tras una etapa en la que se reconocía que "hay que consignarlo, no se ha ido a nuestro campo con un verdadero sentido católico y profesional ${ }^{61}$. Por lo que dejaba traslucir el anónimo gacetillero, la orientación de la comisión había cambiado. El primero de los oradores, el presidente de la Junta Municipal del PNV de la localidad de Ajangiz, el casero Lino Argintxona, insistió en que se trataba de "constituir una sólida unión dentro de los principios católicos, para combatir a todos aquellos que se aprovechaban de los sudores del pobre baserritarra». Argintxona utilizó un lenguaje que los campesinos comprendían sin problemas.

Aunque estas afirmaciones dan a entender que se había producido una reformulación del proyecto nekazari, no parece que la aseveración de Elorza sobre el enfriamiento del interés del PNV por la cuestión agraria tenga demasiado fundamento ${ }^{62}$ a tenor del amplio espacio que le dedicó el diario Euzkadi en los primeros meses del año 1935. Es más, aunque no sabemos quienes se escondían bajo el pseudónimo de "Arantzamendi», la orientación de sus escritos y la de los textos eusquéricos de Ibai-gane (Ciriaco Aberasturi) eran claramente favorables a la constitución del sindicato y a favorecer al campesinado

60 «Miremos también al agro», Euzkadi, 18-11-1934.

61 «Un mitin en Gernika», Euzkadi, 14-5-1935.

62 Elorza (1977). 
arrendatario. En ese mismo sentido resulta paradójico que se afirme que se había producido una ralentización, justo cuando finalmente el proyecto pudo concretarse $^{63}$. La ley de arrendamientos rústicos aprobada por las Cortes derechistas en marzo de 1935 (apoyada parcialmente por el PNV) y la de Reforma de la Reforma Agraria (noviembre de 1935), los desahucios que se produjeron invocándolas, que afectaron en muchos casos a simpatizantes del nacionalismo vasco y la polarización política que alejó aún más al PNV de las derechas españolas, hacían necesario el apoyo a Euzko Nekazari Alkartasuna y no apreciamos indicios de que no fuese así. Los intentos de detener la aplicación de la ley de arrendamientos son una muestra de ello.

El resultado de todas estas actividades fue positivo. Los meses de la primavera de 1935 vieron como se celebraban charlas y mítines en diferentes poblaciones y el 21 de julio se reunieron de nuevo en Markina representantes de las once agrupaciones ya formadas, eligiéndose una junta directiva presidida por Carmelo Gorroño, labrador vecino de Forua, una localidad muy próxima a Gernika ${ }^{64}$. No hemos podido determinar las características socioprofesionales de los miembros de dicho comité, pero al menos Joaquín Olaizola era ingeniero agrónomo, por lo que la referencia a ser una verdadera organización profesional al frente de la cual estaban única y exclusivamente labradores habría, cuando menos, que matizarla, ya que Olaizola, aunque poseía y trabajaba fincas agrícolas, no podía ser considerado un campesino más.

A partir de este momento, Euzko Nekazari Alkartasuna experimentó un crecimiento muy significativo. De esta forma, un año más tarde, en julio de 1936, alcanzó las 31 agrupaciones locales y unos 2600 afiliados ${ }^{65}$. Con la excepción del núcleo de Leioa, el resto de las poblaciones con presencia solidaria se encontraban al este del territorio, en las zonas vascoparlantes más alejadas del núcleo industrial de Bilbao.

Solo tres de esas poblaciones no habían conocido en 1933 el triunfo de la candidatura a Cortes del PNV y únicamente en cinco se vio superada esta lista por la coalición de derechas en 1936. Las cifras de afiliación, no obstante, estaban muy alejadas del eco alcanzado por ENB en Guipúzcoa. Si en esta

63 Ansel (2011): 25.

64 «El domingo quedó constituida Bizkai'ko Euzko-Nekazari-Bazkuna», Euzkadi, 28-7-1935.

65 Abadiano, Ajangiz, Amorebieta, Amoroto, Arbatzegi-Gerrrikaitz, Arratzu, Artea, Arteaga, Berriatua, Berriz, Busturia, Dima, Ermua, Errigoiti, Etxebarri, Foru, Garai, Gizaburuaga, Ibarrangelu, Igorre, Iurreta, Kortezubi, Leioa, Lemona, Markina Mendata, Murelaga, Nabarniz y Zeanuri. 


\section{Mapa 1. Distribución de las agrupaciones locales} de Euzko Nekazari Alkartasuna (1936)

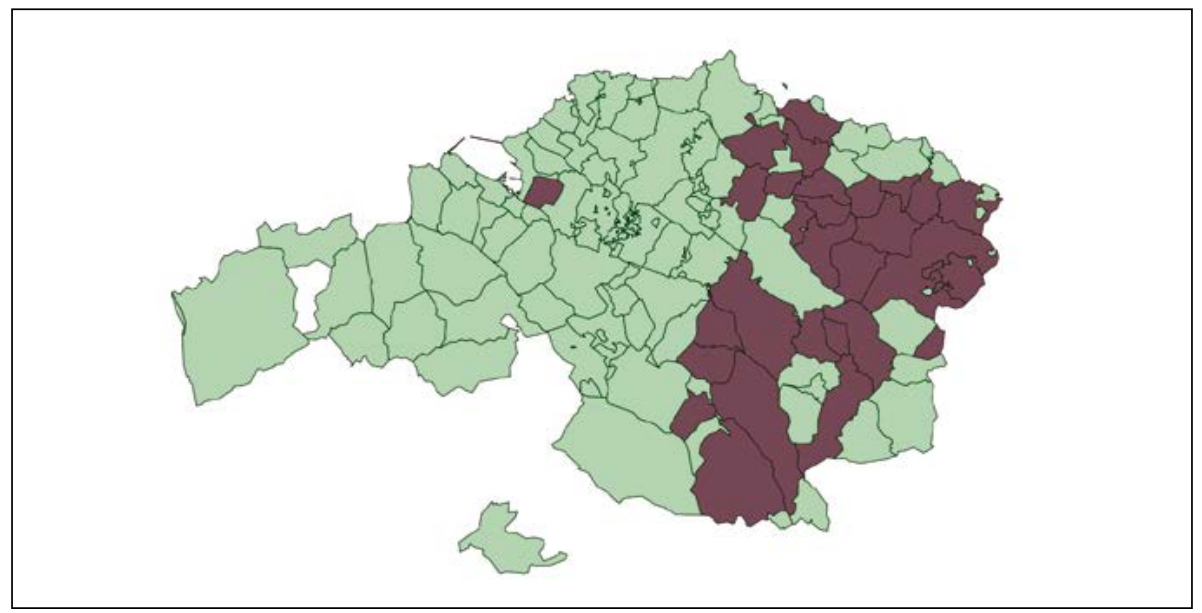

Fuente: elaboración propia a partir de Elorza (1977).

provincia, los nekazaris agrupaban a más del $60 \%$ de los campesinos del territorio, en Vizcaya, donde el voto nacionalista era proporcionalmente más alto, en especial, en el distrito de Vizcaya-provincia, solo lo hacían con un $15 \%$ escaso. No estamos en condiciones de dar una explicación concluyente de esa disparidad, pero probablemente la existencia de un tejido asociativo agrario católico y o independiente más activo en el caso de Vizcaya sea un elemento más solvente para argumentar esa diferencia que la apelación a la desconfianza del PNV ante el movimiento nekazari.

\section{EL DISCURSO NEKAZARI Y LOS LÍMITES DE SU CAPACIDAD DE ATRACCIÓN}

El campesinado parcelario vasco de los años treinta era, fuese o no consciente de ello, fruto de la interacción entre la agricultura, la industria y un pujante sector servicios. Supo adaptarse a la nueva situación comercializando parte de sus productos y abandonando la economía de subsistencia. Esta transformación produjo una alteración sustancial de las relaciones sociales del baserritarra. El intenso contacto con el medio urbano, que le proporcionaba recursos económicos más estables, acarreó, en contrapartida, una pérdida de prestigio social en la medida en que los habitantes de las zonas rurales eran 
ahora mucho más conscientes de las diferencias de nivel de vida existentes entre la ciudad y las zonas rurales y de la incapacidad de estas últimas para satisfacer los nuevos estándares de calidad hegemónicos en la sociedad. El sindicalismo agrario tenía que defender un modelo economicista, que elevase los niveles de beneficio de los campesinos, al mismo tiempo que trataba de mostrar las excelencias de la vida rural frente a aquellos que optaban por abandonarla camino de las urbes de mayor o menor tamaño. Sus impulsores eran conscientes del sobreesfuerzo que exigía mantener un nivel de ingresos suficientes a través de una agricultura comercializada en un entorno en la que la agricultura estaba desprestigiada como ocupación.

Existía, en ese sentido, un doble sentimiento. Por una parte, la reivindicación incluida en el programa de Euzko Nekazari Bazkuna de que pudiera perpetuarse y reproducirse el modo de vida del caserío, pasando este de padres a hijos. El asociacionismo agrario interpelaba de este modo a todos aquellos baserritarras que habían optado por seguir en el caserío y no abandonarlo por un trabajo en la urbe. Consideraban que el modo de vida campesino, una unidad moral en sí mismo, era compatible con su definición de libertad y dignidad humana ${ }^{66}$. Pero, por otra parte, la mejora de las condiciones de vida y, en concreto, de las educativas (construcción de escuela y provisión de maestros), podía favorecer el éxodo rural o, cuando menos, socavar las estructuras familiares tradicionales. Un columnista del diario Euzkadi lo expresó de forma meridianamente clara: la educación que debía proporcionarse a los jóvenes de las zonas rurales no debía facilitar el abandono de estas, sino que pudiesen ayudar de forma efectiva a sus progenitores, sin poner en cuestión, la autoridad y predominio de los mismos ${ }^{67}$. De alguna forma, la emancipación de la clase agrícola exigía su aislamiento, algo que también se produjo en lugares como Bélgica ${ }^{68}$.

Algunos de los analistas del agrarismo nacionalista y del católico han subrayado la filosofía armonicista que subyace a los planteamientos aprobados en las diferentes asambleas del sindicalismo nacionalista y su defensa de la paz social y de la importancia del derecho de propiedad, frente a lo defendido por los sindicatos de clase ${ }^{69}$. Independientemente del hecho de que el sindicalismo de clase (socialista o anarquista) fue casi inexistente en la vertiente cantábrica, no hay que minusvalorar las tensiones que provocó en el agro vasco la irrupción de los nekazaris. La aparición de una nueva oferta sociopolítica alteró la

66 Greenwood (1998): 194.

67 «La educación profesional de nuestro nekazari», Euzkadi, 26-5-1935.

68 Van Molle (1990): 375.

69 González (2006). 
relación entre los diferentes colectivos campesinos, entre aquellos que se adhirieron a ENB y a ENA y aquellos que se mantuvieron fieles al asociacionismo católico no reivindicativo o a sus tradiciones políticas (el carlismo) o simplemente no se habían incorporado a ninguna estructura asociativa.

Para muchos campesinos la nueva realidad asociativa representaba la llegada de un mundo que reputaban extraño, con planteamientos que rompían con la forma de vida tradicional, que destruían la unanimidad y homogeneidad que, según ellos, había caracterizado la época anterior y cuestionaban el monopolio del poder por parte de determinadas elites rurales. La irrupción de «la política» como elemento de la vida cotidiana que rompía el consenso campesino y no como algo que sucedía cada pocos años en el día de las elecciones generales, la constante movilización que se les exigía, el nuevo lenguaje y las nuevas actitudes y actores que protagonizaron el cambio también fueron vistos con aprensión por algunos sectores.

Por otra parte, ya en el mismo año 1933, y pese a las protestas de apoliticismo y moderación, se generaron las primeras tensiones entre nekazaris y los sectores vinculados a los propietarios y a la derecha monárquica y tradicionalista. Así, en octubre de ese año se produjo una reunión de la Agrupación Agropecuaria de Guipúzcoa en la que se criticó duramente la actuación de la directiva de ENB. Como no se trataba de la primera ocasión que se producía ese tipo de procedimiento, "confundiendo conceptos y falseando los hechos, pretendiendo desacreditar ante sencillos nekazaris a honorables propagandistas que se sacrifican por ideales más altos y sagrados», la agrupación local retó a la agrupación a una controversia pública, que por los datos que tenemos no llegó a producirse ${ }^{70}$. No pensamos que estas malas relaciones provocasen una situación de conflictividad cotidiana equiparable a la producida en otras zonas de Espańa, al menos hasta enero de 1936, momento en que se produjeron varios desahucios en aplicación de la Ley de Arrendamientos.

\section{CONCLUSIÓN}

El movimiento agrarista en la cornisa cantábrica vasca tuvo como objetivos fundamentales conseguir el acceso de los baserritarras arrendatarios a la propiedad de sus explotaciones, dignificar el modo de vida campesino y mejorar sus condiciones materiales. Su desarrollo fue un proceso irregular, tanto en el espacio como en el tiempo. Dicho proceso se inició y se consolidó en Guipúzcoa, mientras que tuvo una menor penetración en Vizcaya. El movimiento

70 «Arrasate», Euzkadi, 15-10-1933. 
tuvo su origen en un núcleo muy concreto, la localidad de Azpeitia en la década de 1920 y solo pudo extenderse, ya en los ańos republicanos, cuando se produjo la combinación de la autoorganización campesina con el apoyo de una fuerza política emergente, el nacionalismo vasco. Ahora bien, es un error considerar al PNV como el agente inspirador de este fenómeno sociopolítico o como su dinamizador fundamental.

Las dificultades encontradas por este movimiento para encuadrar a los campesinos, incluso en Vizcaya, donde electoralmente el nacionalismo vasco era la fuerza más importante, cuando no la hegemónica, refuerzan la tesis de Jordi Planas sobre la inexistencia de una adhesión incondicional del campesinado a otros grupos o de una subordinación política del mismo ${ }^{71}$. Tanto el caso guipuzcoano como el vizcaíno demuestran que los campesinos parcelarios vascos solo se encuadraron en el nuevo societarismo cuando fueron sus iguales los que realizaron dicho llamamiento y, aún entonces, encontraron numerosas resistencias, ya que ni la sociabilidad agraria ni la movilización social constituían sus preocupaciones principales y, además, existía una red mutualista previa, cuya eficacia no se debe descartar sin más. Solo la labor de persuasión realizada a través de la prensa, los mítines y conferencias insistiendo en las ventajas de la asociación, la propia actividad nekazari, cuando pudo estructurarse en el ámbito local, y una coyuntura política, el Bienio 1934-1936, que reforzó el poder de los propietarios frente a los arrendatarios, dieron como resultado una progresiva consolidación del sindicalismo agrario filonacionalista. Este movimiento necesitó un apoyo urbano, que no podemos medir debido a la penuria de fuentes, y aunque no provocó una ruptura radical en el seno de la comunidad campesina, si provocó algunas tensiones importantes a lo largo de 1936.

La aparición de este movimiento debe encuadrarse, por otra parte, en el proceso de crecimiento y complejización ideológica y social del nacionalismo vasco. En la medida en que esta corriente política fue ampliando su eco entre las distintas capas de la sociedad vasca, tuvo que hacerse más receptivo a las reivindicaciones de cada una de ellas, lo que provocó de forma inevitable un aumento de las tensiones intrapartidistas. Esta realidad es apreciable, hasta cierto punto, en el sindicalismo industrial, en Solidaridad de Trabajadores vascos. En lo que respecta al movimiento agrarista no pensamos, sin embargo, que su aparición y desarrollo provocasen en el periodo republicano especiales problemas de cohesión y de coherencia entre la actuación del PNV y de los dirigentes nekazaris.

No es sencillo realizar una valoración de todas estas actuaciones. Siempre es peligroso atribuir a una única razón las claves de un fenómeno social.

71 Planas (2010): 81-82. 
Junto a los efectos de la propaganda societaria hay un sinnúmero de elementos que interactúan en los espacios sociales. La irrupción de la Guerra Civil provocó la desaparición de un conjunto de potencialidades que apenas estaban empezando a desarrollarse. Los actores sociales que participaron en el movimiento agrarista vasco estudiado en estas páginas lo hicieron desde unos presupuestos que eran hijos de un tiempo, un espacio y un pensamiento determinados, y partiendo de un universo simbólico, de un repertorio de recursos para la acción colectiva, de una estructura de oportunidad política y de unos mecanismos de movilización necesariamente limitados. Dudo mucho de que en su mayoría fuesen capaces de distinguir cuando actuaban como nacionalistas, como sindicalistas o como simples campesinos. Las tensiones que pudiesen existir por su actuación en cada uno de esos papeles eran mucho menores que las surgidas entre ellos y otros grupos políticos y sociales, y aún estas fueron más moderadas que las producidas en otros entornos rurales españoles.

\section{Bibliografía}

Andrés-Gallego, J. (1984). Pensamiento y acción social de la Iglesia en España. Madrid: Espasa. Ansel, D. (2011). Los nekazaris vascos durante la II República: Nacionalismo y clase, tradición y modernidad. En XIII Congreso de Historia Agraria. Lleida: Universitat de Lleida. Disponible en: http://seha.info/congresos/2011/S3-Ansel,\%20Dario.pdf.

Arrieta, L. (1998). El Movimiento Cooperativo en Euskadi. Bilbao: Fundación Sabino Arana. Balparda, G. de (1935). La Aplicación de las leyes de reforma agraria en Vizcaya: memoria inaugural del curso de 1935-36 leída el 19 de octubre. Bilbao: Academia de Derecho y Ciencias Sociales.

Beltrán Tapia, F. J. (2012). Commons, social capital, and the emergence of agricultural cooperatives in early twentieth century Spain. European Review of Economic History, 16, 511-528. Disponible en: https://doi.org/10.1093/ereh/hes014.

Berriochoa Azcarate, P. (2014). Como un jardin: el caserio guipuzcoano entre los siglos XIX y XX. Leioa: Universidad del País Vasco.

Cabo Villaverde, M. (2009). Galeguismo, agro e agrarismo na Galicia da II República. Cuadernos de Estudios Galegos, LVI-122, 371-389. Disponible en: https:/doi.org/10.3989/ ceg.2009.v56.i122.69.

- (2011). Acción gallega: Populismo agrario y politización del campesinado en la Galicia de la Restauración. En XIII Congreso de Historia Agraria. Lleida: Universitat de Lleida. Disponible en http://seha.info/congresos/2011/S3-Cabo,\%20Miguel.pdf.

Delgado Cendagortagalarza, A. (2009). Trabajo y vida cotidiana en la "Otra» Bizkaia, 18761923. Madrid: Catarata.

Diaz Noci, J. (2001). Argia. Euskal astekari baten historia (1921-1936). Leioa: Egileak. 
Egidazu y Garai, T. de (1932). El caserio y su venta a los inquilinos. La ley agraria, su inaplicación en Euzkadi y consecuencias si se alquilase. Bilbao: Talleres Gráficos E. Verdes Achirica.

Elorza, A. (1977). El tema rural en los orígenes literarios del nacionalismo vasco. En Actas del Quinto Congreso Internacional de Hispanistas: celebrado en Bordeaux del 2 al 8 de septiembre de 1974 (pp. 355-376). Burdeos: Université de Bordeaux III.

Etxeberria Lasa, X. (2015). El cooperativismo católico agrario en las provincias vascas, 19061936. Barcelona: Master de Historia Económica. Universitat de Barcelona.

Federación Católica Agraria de Vizcaya. (1921). Memoria correspondiente al año 1920, leída y aprobada en la Asamblea anual de los sindicatos federados el día 11 de enero de 1921. Bilbao: Imprenta de G. Ibáñez.

Fernández Prieto, L., et al. (1997). O proceso de adaptación do mundo agrario ó capitalismo. En VV. AA. Galicia fai dous mil anos. O feito diferencial galego (pp. 201-218). Santiago, Museo do Pobo Galego.

Garrido Herrero, S. (2003). El primer cooperativismo agrario español. CIRIEC. Revista de Economía Pública, Social y Cooperativa, 44, 33-56.

- (2007). Why Did Most Cooperatives Fail? Spanish Agricultural Cooperation in the Early Twentieth Century. Rural History, 18 (2), 183-200. Disponible en: https://doi. org/10.1017/S0956793307002142.

Gobierno Vasco. (2009). 117 urte nekazari ganberak Euskadin. 117 años de Cámaras Agrarias en Euskadi. Gasteiz: Eusko Jaurlaritza.

González Castillejo, M. J. (2006). ¿Una respuesta al caciquismo? Los sindicatos católicos en el universo rural malagueño (1923-1930). En J. M. Ortíz de Orruño, et al. (comps.). Movimientos sociales en la España contemporánea (pp. 433-457). Madrid: Adaba.

Greenwood, D. (1998). Hondarribia: riqueza ingrata (comercialización y colapso de la agricultura). Bilbao: EHU.

Ibañez García, G. y Vidaurrazaga Acha, V. (1934). Desarrollo y prosperidad de la Provincia de Vizcaya. Bilbao: J. Álvarez.

Instituto de Reformas Sociales. (1915). Avance al Censo de Asociaciones del Instituto de Reformas Sociales. Madrid: Imp. de la suc. de M. Minuesa de los Ríos.

Juaristi Larrinaga, P. (2011). Markinako frontea. Markinako eta Xemeingo egoera politikoa eta soziala Bigarren Errepublikan eta Gerra Zibilean (1931-1939). Bilbo: EHU.

Legorburu Faus, E. (1993). La crisis del caserío. Situación del agro guipuzcoano en torno a 1930. BRSBAP, 49 (2), 369-410.

Lynch, É. (2009). Pour et par le paysan. La movilización agraria en la Francia de entreguerras. Historia Agraria, 49, 133-160.

Majuelo, E. y Pascual, A. (1991). Del catolicismo agrario al cooperativismo empresarial. Setenta y cinco años de la Federación de cooperativas navarras, 1910-1985. Madrid: Ministerio de Agricultura.

Mayayo, A. (1995). De pagesos a ciutadans. Cents anys de sindicalisme i cooperatisme agraris a Catalunya (1893-1994). Catarroja: Afers.

Mikelarena, F. (1993). El proceso de urbanización en el País Vasco peninsular entre 1860 y 1930. Vasconia, 21, 413-434. 
Muñiz, L. (1927). La Acción Social Agraria en España. Estado actual de la agricultura, importancia de la Asociación y cooperación y necesidad del crédito agrícola. Madrid: Imprenta Palomeque.

Pejenaute Goñi, J. M. (1989). Desarrollo del cooperativismo agrario navarro desde la Federación a la Confederación (1910-1917). Príncipe de Viana, 50 (188), 649-686.

Planas, J. (2010). Identidades, corporativismo y autonomía del campesinado en la acción colectiva agraria. Cataluña, 1890-1920. Historia Agraria, 50, 65-90.

Pomés, J. (1995). La Unió de Rabassaires. Barcelona: Abadia de Montserrat.

Prada Rodríguez, J. (2006). Ni tan viejo, ni tan nuevo: Conflictividad y protesta social en el rural ourensano (1931-1936). En J. M. Ortíz de Orruño, et al. (comps.). Movimientos sociales en la España contemporánea (pp. 505-523). Madrid: Adaba.

Rodríguez Ranz, J. A. (1994). Guipúzcoa y San Sebastián en las elecciones de la II República. San Sebastián: Fundación Kutxa.

Román Cervantes, C. (2015). Agricultural cooperatives in Spain, between failure ans sucess? (1890-2001). Madrid: AEHE.

Ruiz Urrestarazu, E. (1985). La distribución de los terrenos comunales en Álava. Lurralde: Investigación y espacio, 8, 189-196.

Sanz Legaristi, P. y Reboredo Olivenza, D. (1985). El sindicalismo agrario en Álava (19051924). Kultura, 8, 90-104.

Utanda Moreno, L. y Feo Parrondo, F. (1996). Propiedad rústica en Vizcaya según el registro de la propiedad expropiable (1933). Lurralde: Investigación y espacio, 19, 65-87.

Van Molle, L. (1990). Chacun pour tous: le Boerenbond Belge 1890-1990. Leuven: Universitaire Pers Leuven. 